\title{
Ultrafiltration for intractable ascites after liver transplantation
}

\author{
G Noble-Jamieson, N Jamieson, N D Barnes
}

\begin{abstract}
A 5.7 year old boy with $\alpha_{1}$-antitrypsin deficiency developed intractable ascites after liver transplantation. Conservative treatment was unsuccessful and after 18 days concentrated ascitic fluid was reinfused intravenously using a Gambro haemofilter. The ascitic loss resolved rapidly. This new method of ultrafiltration proved simple and effective.
\end{abstract}

\section{Case report}

Severe intractable ascites was the main indication for liver transplantation in a 5.7 year old boy with $\alpha_{1}$-antitrypsin deficiency. After the operation the ascites returned and massive amounts were lost through the abdominal drains from the fourth postoperative day. The next day the serum bilirubin concentration and ,alanine transaminase activity rose and ultra'sound Doppler demonstrated poor hepatic compliance. These are all indications of possible acute rejection.

A liver biopsy specimen confirmed moderately severe rejection and treatment with high dose intravenous methylprednisolone was.given for three days. There was a rapid response with

(Arch Dis Child 1991;66:988-9) Cambridge CB2 200 N Jamieson N D Barnes

Correspondence to: Correspondence to:
Dr Noble-Jamieson
Paediatrics and Surgery, Addenbrooke's Hospita the liver function tests returning to normal within seven days. The ascitic fluid losses, however, increased to a maximum of $10 \mathrm{~V} /$ day. The fluid lost was a sterile exudate which contained $39 \mathrm{~g} / \mathrm{l}$ of protein. Repeated examinations with ultrasound Doppler excluded obstruction of the inferior vena cava and the hepatic and portal venous systems. Despite massive replacement with blood products the protein loss caused a severe coagulopathy (fig 1). From the 11th day all ascitic fluid loss was reinfused intravenously. This rapidly corrected the coagulopathy but the volume of ascites remained the same (fig 1).

After 18 days it was decided to concentrate the ascitic fluid using a Gambro Haemofilter FH22 (Gambro Dialysatoren) before reinfusion. In a closed circuit the ascitic fluid was drained through a peritoneal catheter, then pumped across the haemofilter membrane. The protein concentrate was then reinfused through a blood transfusion filter (Pall) into a femoral vein (fig 2). The volumetric infusion pump (IMED) was set at a rate between 100 and $600 \mathrm{ml} /$ hour, starting with a high rate initially while the abdomen was grossly distended and decreasing as the abdominal girth diminished. The filtrate, which varied in volume from 100 to $150 \mathrm{ml}$ hour, was discarded. The haemofilter was perfused with heparin at a dose of 100 units/ hour to prevent blockage of the filter and clot formation in the ascitic fluid. No prophylactic antibiotic treatment was used and ascitic fluid sent daily for culture remained sterile. Transient hyponatraemia and oliguria occurred on the third day of the procedure but the serum urea and creatinine concentrations remained stable. After six days the abdominal girth had decreased from $80 \mathrm{~cm}$ to $65 \mathrm{~cm}$ and ultrafiltration was stopped. Subsequently there was only slight ascitic drainage, and this ceased entirely after two days.

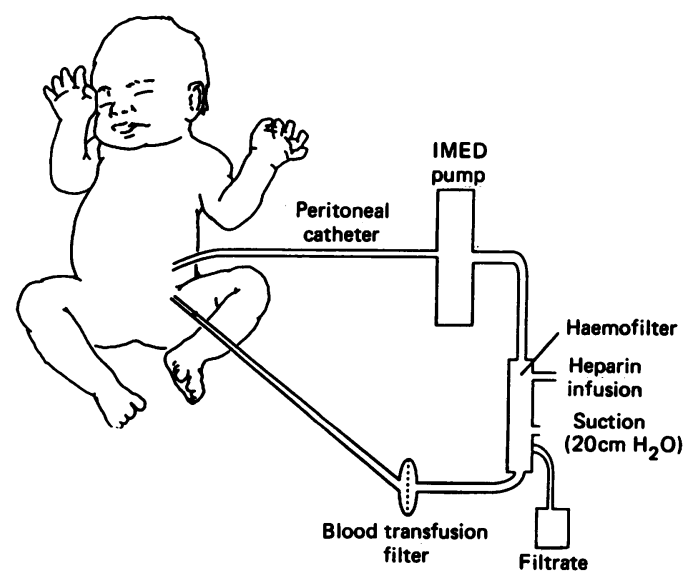

Figure 2 Circuit for ultrafiltration and reinfusion of ascites.

Figure 1 Blood product requirements and changes in prothrombin time in relation to ascitic fluid losses. 


\section{Discussion}

In liver cirrhosis ascites formation is a consequence of progressive intrahepatic venous obstruction, leading to a rise in intrasinusoidal pressure and increased hepatic lymph production. ${ }^{1}$ Another important mechanism is the hyperaldosteronism and urinary sodium retention which occurs in response to the depletion of the vascular space. ${ }^{12}$ Even when there has been gross ascites preoperatively it generally resolves promptly after successful liver transplantation. Among 120 recipients of paediatric liver transplant, only three children have developed severe postoperative ascites, on each occasion in association with acute graft rejection. Ultrasound Doppler studies have proved extremely useful in the early diagnosis of acute rejection by demonstrating a reduction in hepatic venous pulsatility, indicating a swollen and noncompliant liver. ${ }^{3}$ These changes reflect reduced hepatic venous outflow and ascites formation may follow. Depletion of the intravascular space leads to renin, angiotensin, and aldosterone secretion and so to urinary sodium retention. This secondary hyperaldosteronism probably contributes to prolonged ascitic loss even after a rejection episode had resolved. It seems probable also that the severe preoperative ascites may have opened channels for ascitic fluid production.

Thus the rapid development of ascites after liver transplantation may indicate the onset of acute graft rejection. When venous obstruction has been excluded a liver biopsy is needed. Management should include control of the rejection and treatment of the ascites. Replacement of large volumes of plasma proteins may be required to replenish the intravascular volume, to maintain normal coagulation, and to maintain humoral immunity. Diuretics, especially aldosterone antagonists such as spironolactone, are usually given to counteract the secondary hyperaldosteronism. When these forms of treatment prove inadequate it seems logical to replace the ascitic fluid loss, and various methods of reinfusion and ultrafiltration have been described. ${ }^{4-6}$ The ultrafiltration device most commonly described has been the Rodiascit system, which allows continuous ultrafiltration and reinfusion of the concentrated ascites. We used a less complicated and more readily available method for ultrafiltration of ascites. Continuous arteriovenous haemofiltration is a well established technique and is frequently used for patients with oliguria and fluid overload. The haemofilter removes water and crystalloids with a molecular weight below 15000 . Filtration is usually driven by arterial pressure alone but can be enhanced by a pump and this was of course needed to circulate the ascitic fluid. By recycling the ascites in this way protein losses were avoided and the clotting deficit was rapidly corrected. Immunoglobulins and complement are also lost in ascitic fluid and their retention reduces the risk of infection. To our knowledge this method of ultrafiltration of ascites has not been used before and it proved remarkably simple, practical, and effective.

We thank the nursing staff of the paediatric intensive care unit for their technical advice and expertise in caring for this patient.

1 Epstein M. Pathophysiology of ascites formation. In: Epstein M, ed. The kidney in liver disease. Baltimore: Williams and Wilkins, 1988:209-43.

2 Epstein $M$. The sodium retention of cirrhosis: a reappraisal. Hepatology 1986;6:312-5.

3 Coulden RA, Britton PD, Farman P, Noble-Jamieson G, Wight DGD. Preliminary report: hepatic vein Doppler in the early diagnosis of acute liver transplant rejection. Lancet 1990;336:273-5.

4 Assadi FK, Gordon D, Kecskes SA, John E. Treatment of refractory ascites by ultrafiltration-reinfusion of ascitic refractory ascites by ultrafiltration-reinfusion
fluid peritoneally. $\mathcal{F}$ Pediatr $1985 ; 106: 943-6$.

5 Levy VG, Opolon P, Pauleau N, Caroli J. Treatment of ascites by reinfusion of concentrated peritoneal fluid review of 318 procedures in 210 patients. Postgrad Med F 1975;51:564-6.

6 Parbhoo SP, Ajdukiewicz A, Sherlock S. Treatment of ascites by continuous ultrafiltration and reinfusion of protein concentrate. Lancet 1974;i:949-52. 